Jonathan 0. Bauer*

\title{
The crystal structure of adamantylmethoxydiphenylsilane, $\mathrm{C}_{23} \mathrm{H}_{28} \mathrm{OSi}$
}

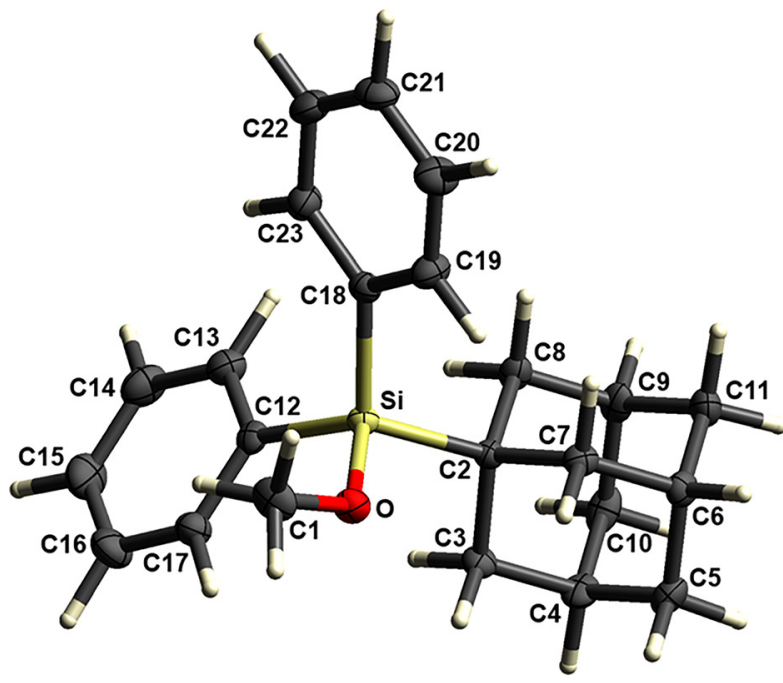

https://doi.org/10.1515/ncrs-2021-0243

Received June 11, 2021; accepted June 24, 2021; published online July 12, 2021

\section{Abstract}

$\mathrm{C}_{23} \mathrm{H}_{28} \mathrm{OSi}$, monoclinic, $P 2_{1} / c$ (no. 14), $a=14.2882(11) \AA$, $b=17.8169(10) \AA, c=7.6201(6) \AA, \beta=103.780(8)^{\circ}$, $V=1884.0(2) \AA^{3}, Z=4, R_{g t}(F)=0.0538, w R_{r e f}\left(F^{2}\right)=0.1241$, $\mathrm{T}=173(2) \mathrm{K}$.

\section{CCDC no.: 2091881}

The molecular structure (left part) and the two-dimensional (2D) fingerprint plot (right part; showing all contributions of intermolecular contacts) of the title compound are shown in the figure. Table 1 contains crystallographic data and Table 2 contains the list of the atoms including atomic coordinates and displacement parameters.

\section{Source of material}

The title compound was obtained as a by-product in the reaction of adamantyltrimethoxysilane with phenyllithium

*Corresponding author: Dr. Jonathan 0. Bauer, Institut für Anorganische Chemie, Fakultät für Chemie und Pharmazie, Universität Regensburg, Universitätsstraße 31, D-93053 Regensburg, Germany, E-mail: jonathan.bauer@ur.de. https://orcid.org/0000-0002-95757430

Ә Open Access. ( 2021 Jonathan O. Bauer, published by De Gruyter. (cc) BY International License.

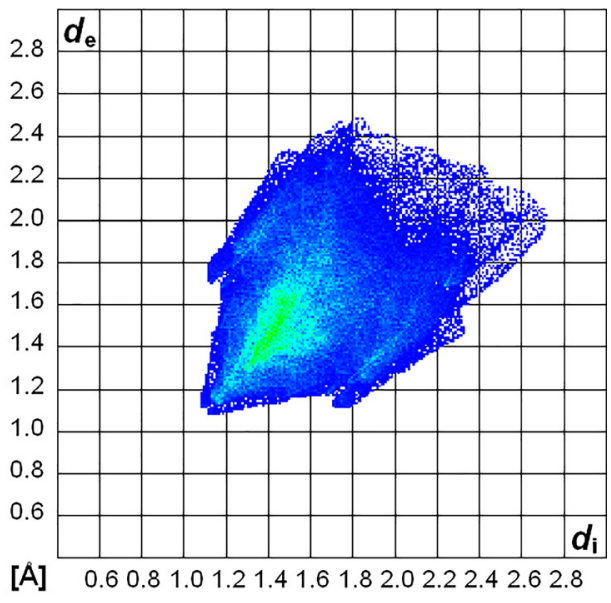

Table 1: Data collection and handling.

\begin{tabular}{ll}
\hline Crystal: & Colorless block \\
Size: & $0.30 \times 0.20 \times 0.20 \mathrm{~mm}$ \\
Wavelength: & Mo $K \alpha$ radiation $(0.71073 \AA$ A $)$ \\
$\mu:$ & $0.13 \mathrm{~mm}^{-1}$ \\
Diffractometer, scan mode: & Xcalibur, $\omega$ \\
$\theta_{\max }$, completeness: & $29.9^{\circ},>99 \%$ \\
$N\left(h k l_{\text {measured }}, N\left(h k l l_{\text {unique }}, R_{\text {int }}:\right.\right.$ & $15475,4795,0.054$ \\
Criterion for $I_{\text {obs }}, N(h k l)_{\text {gt }}:$ & $I_{\text {obs }}>2 \sigma\left(I_{\text {obs }}\right), 3241$ \\
$N(\text { param })_{\text {refined }}:$ & 338 \\
Programs: & CrysAlis \\
& Olex2 [6], WinGX/ORTEP [7], SHELX [2-5], \\
& CrystalExplorer17 [8-10] \\
\hline
\end{tabular}

in diethyl ether/dibutyl ether. Crystals suitable for singlecrystal X-ray diffraction analysis were obtained after filtration from a concentrated solution of the crude mixture in diethyl ether/dibutyl ether at room temperature within one day.

\section{Experimental details}

Single-crystal X-ray diffraction analysis of adamantylmethoxydiphenylsilane was performed on an Oxford Diffraction CCD Xcalibur S Diffractometer equipped with a Sapphire3 CCD detector at 173(2) K using graphitemonochromated Mo-K $\alpha$ radiation $(\lambda=0.71073 \AA)$. Data 
Table 2: Fractional atomic coordinates and isotropic or equivalent isotropic displacement parameters $\left(\AA^{2}\right)$.

\begin{tabular}{|c|c|c|c|c|}
\hline Atom & $x$ & $y$ & $z$ & $U_{\text {iso }} * / U_{\text {eq }}$ \\
\hline 1 & 0.39183 (18) & 0.55609 (15) & $0.1620(3)$ & $0.0302(5)$ \\
\hline $1 \mathrm{~A}$ & $0.344(2)$ & $0.5666(15)$ & $0.056(4)$ & $0.059(8)^{\star}$ \\
\hline 1B & 0.4165 (19) & $0.6019(17)$ & $0.218(4)$ & $0.066(9)^{*}$ \\
\hline $1 C$ & $0.439(2)$ & $0.5273(15)$ & $0.124(4)$ & $0.068(9)^{*}$ \\
\hline $\mathrm{C} 2$ & $0.24224(12)$ & 0.46467 (10) & $0.5219(3)$ & $0.0161(4)$ \\
\hline C3 & $0.32901(14)$ & $0.42936(11)$ & $0.6591(3)$ & 0.0207 (4) \\
\hline $3 \mathrm{~A}$ & 0.3568 (13) & $0.4667(11)$ & $0.747(3)$ & $0.016(5)^{\star}$ \\
\hline $3 B$ & $0.3788(14)$ & $0.4143(11)$ & 0.596 (3) & $0.022(5)^{\star}$ \\
\hline-4 & 0.29661 (15) & $0.36154(11)$ & $0.7538(3)$ & $0.0241(5)$ \\
\hline 14 & $0.3512(15)$ & $0.3431(11)$ & $0.838(3)$ & $0.028(6)^{\star}$ \\
\hline $\mathrm{C} 5$ & $0.25269(16)$ & $0.30202(11)$ & $0.6134(3)$ & $0.0245(5)$ \\
\hline $\mathrm{H} 5 \mathrm{~A}$ & $0.2360(15)$ & $0.2583(13)$ & $0.678(3)$ & $0.032(6)^{*}$ \\
\hline $5 B$ & 0.3009 (14) & 0.2857 (11) & 0.547 (3) & $0.024(5)^{\star}$ \\
\hline 6 & 0.16531 (14) & $0.33542(11)$ & $0.4792(3)$ & $0.0210(4)$ \\
\hline H6 & 0.1391 (14) & $0.2974(11)$ & $0.388(3)$ & $0.022(5)^{*}$ \\
\hline$C 7$ & $0.19733(15)$ & $0.40326(11)$ & 9 (3) & $0.0200(4)$ \\
\hline $17 \mathrm{~A}$ & $0.1404(15)$ & $0.4241(11)$ & 7 (3) & $5(6)^{\star}$ \\
\hline A7B & $0.2417(14)$ & $0.3882(10)$ & $0.319(3)$ & $0.016(5)^{\star}$ \\
\hline 8 & 0.16617 (14) & $0.48869(10)$ & 0.62 & $0.0206(4)$ \\
\hline $\mathrm{H} 8 \mathrm{~A}$ & 0.1951 (13) & $0.5292(11)$ & $0.718(3)$ & $0.020(5)^{*}$ \\
\hline 48B & $0.1072(13)$ & 0.5 & (3) & $0.016(5)^{\star}$ \\
\hline C9 & $0.13449(15)$ & $0.42015(11)$ & 0.722 & $0.0243(5)$ \\
\hline H9 & 0.0889 (14) & $0.4350(10)$ & (3) & $0.019(5)^{\star}$ \\
\hline 10 & $0.22228(17)$ & $0.38702(12)$ & 0.85 & $0.0276(5)$ \\
\hline $\mathrm{H} 10 \mathrm{~A}$ & 0.2037 (15) & 0.3459 (12) & $0.919(3)$ & $3(6)^{\star}$ \\
\hline H10B & 0.2484 (14) & $0.4237(12)$ & $0.948(3)$ & $8(6)^{*}$ \\
\hline C11 & 0.09054 (15) & 0.36089 (12) & 0.581 & $0.0256(5)$ \\
\hline $\mathrm{H} 11 \mathrm{~A}$ & $0.0668(13)$ & $0.3167(11)$ & (3) & $0.021(5)^{\star}$ \\
\hline H11B & $0.0357(15)$ & $4(11)$ & (3) & $0.027(6)^{\star}$ \\
\hline 12 & 0.35666 (14) & $0.61289(10)$ & $0.5 \varepsilon$ & 0.0187 (4) \\
\hline 13 & $0.31701(16)$ & $0.66250(11)$ & $0.6927(3)$ & $0.0258(5)$ \\
\hline 13 & 0.2460 & 0.6654 & (3) & $0.016(5)^{*}$ \\
\hline 14 & $0.37521(17)$ & 0.70776( & 34 (3) & $32(5)$ \\
\hline 14 & 0.3469 (17) & & & $5(7)^{\star}$ \\
\hline 15 & $0.47464(17)$ & 0.70 & 0.85 & $53(6)$ \\
\hline 115 & $0.5165(15)$ & $0.7379(13)$ & $0.940(3)$ & $0.037(6)^{\star}$ \\
\hline 16 & $0.51568(16)$ & $0.65382(12)$ & $0.7546(3)$ & $0.0329(5)$ \\
\hline H16 & $0.5877(16)$ & $0.6495(12)$ & $0.777(3)$ & $0.033(6)^{\star}$ \\
\hline C17 & $0.45751(14)$ & 0.60918 (11) & $0.6237(3)$ & $0.0236(5)$ \\
\hline H17 & 0.4885 & $0.5762(11)$ & $2(3)$ & $0.022(5)^{\star}$ \\
\hline C18 & $0.18264(13)$ & $0.59858(10)$ & $0.2527(3)$ & $0.0187(4)$ \\
\hline C19 & $0.13572(15)$ & 0.56110 & 0.093 & $0.0260(5)$ \\
\hline H19 & $0.1561(15)$ & $0.5114(13)$ & $0.071(3)$ & $0.035(6)^{\star}$ \\
\hline $\mathrm{C} 20$ & $0.06044(16)$ & $0.59322(12)$ & $-0.0340(3)$ & $0.0302(5)$ \\
\hline $\mathrm{H} 2 \mathrm{O}$ & $0.0275(17)$ & $0.5634(13)$ & $-0.146(3)$ & $0.045(7)^{\star}$ \\
\hline $\mathrm{C} 21$ & 0.02969 (15) & $0.66508(12)$ & $-0.0058(3)$ & $0.0294(5)$ \\
\hline $\mathrm{H} 21$ & $-0.0262(15)$ & $0.6865(12)$ & $-0.094(3)$ & $0.034(6)^{\star}$ \\
\hline $\mathrm{C} 22$ & $0.07570(15)$ & $0.70426(12)$ & $0.1470(3)$ & $0.0292(5)$ \\
\hline $\mathrm{H} 22$ & 0.0544 (15) & $0.7541(14)$ & $0.163(3)$ & $0.037(6)^{\star}$ \\
\hline $\mathrm{C} 23$ & $0.15084(15)$ & $0.67164(11)$ & $0.2746(3)$ & $0.0248(5)$ \\
\hline H23 & 0.1797 (15) & $0.7006(12)$ & $0.380(3)$ & $0.030(6)^{\star}$ \\
\hline 0 & $0.35523(9)$ & $0.51318(7)$ & $0.28997(18)$ & $0.0217(3)$ \\
\hline Si & $0.28431(4)$ & $0.54843(3)$ & $0.41056(7)$ & $0.01617(14)$ \\
\hline
\end{tabular}

collection and reduction were performed using the CrysAlisPro software system, version 1.171.36.24 [1]. The crystal structure was solved with SHELXT 2018/2 using Olex2 $[2,3,6]$. The crystal structure was refined based on $F^{2}$ (SHELXL-2018/3) [3-5] using Olex2 [6] and the SHELX program package as implemented in WinGX [7]. A multi-scan absorption correction using spherical harmonics as implemented in SCALE3 ABSPACK was employed [1]. The hydrogen atoms were located on the difference Fourier map and refined independently. The Hirshfeld surface [8] was mapped over $d_{\text {norm }}$ ranging from 0.0222 to 1.3228 a.u. $d_{i}$ and $d_{e}$ in the $2 \mathrm{D}$ fingerprint diagram [9] are the distances from the surface to the nearest atom interior and exterior to the surface, respectively, and are each given in the range of 0.4-3.0 $\AA$. The molecular structure and the 2D fingerprint plot of the title compound, shown in the figure, were created using CrystalExplorer 17.5 [10].

\section{Comment}

Methoxysilanes are common building blocks with many applications in preparative chemistry, e.g. they are used to form polymers [11] and silica-based materials [12], and for the silylation of surfaces $[13,14]$. They are also widely used as valuable coupling reagents $[15,16]$ for the controlled design of polysiloxanes $[17,18]$, as synthesis intermediates [19-21], and for the construction of specially functionalized methoxysilanes [22-28] and siloxanes [22, 23, 26, 29, 30]. We recently reported an in-depth structural study on the involvement of the tert-butyldiphenylsilyl (TBDPS) moiety in intermolecular interaction pattern in the crystalline state [31]. Bulky and rigid silyl moieties play an important role in protecting group chemistry [32] and the TBDPS group has therefore become an indispensable component for protecting functional groups in organic total synthesis [33, 34].

Herein, the crystal structure of adamantylmethoxydiphenylsilane is presented, i.e. a bulkier analog of tertbutylmethoxydiphenylsilane described previously [31]. There is one title molecule in the asymmetric unit (see the left part of the Figure). The comparison with the recently described tert-butyl derivative [31] shows that the replacement of a tert-butyl group by an adamantyl group has no significant influence on the intramolecular structural parameters. Both compounds deviate only slightly from an ideal tetrahedral coordination around the silicon atom. The $\mathrm{Si}-\mathrm{C} 2$ bond length from the silicon atom to the 
adamantyl group is $1.8844(18) \AA$, which is similar to the corresponding bond length of 1.8889(16) ^̊ in the tert-butyl compound [31].

The intermolecular interaction pattern of the title compound shows some differences compared to that reported for the tert-butyl derivative [31]. In general, due to the higher steric demand of the adamantyl group, the title compound is less densely packed than the tert-butyl compound, which can be seen at the dotted region in the $2 \mathrm{D}$ fingerprint plot indicating large distances for a number of $\mathrm{H} \cdots \mathrm{H}$ and $\mathrm{H} \cdots \mathrm{C}$ contacts (see the figure) [9]. The shortest $\mathrm{H} \cdots \mathrm{H}$ contact (2.377 ̊̊) can be found between the adamantyl (H1OB) and a phenyl group (H19). C-H $\cdots \mathrm{C}(\pi)$ contacts are important structure-determining interactions $[31,35,36]$. The small wings that can be attributed to edge-shifted $\mathrm{C}(\operatorname{aryl})-\mathrm{H} \cdots \mathrm{C}(\pi)$ contacts are also somewhat more pronounced here than for the tert-butyl compound [31], with the closest $\mathrm{H} \cdots \mathrm{C}$ contact being found for $\mathrm{C} 14-\mathrm{H} 14 \cdots \mathrm{C} 13$ (2.948 $\AA$ ). In addition, the adamantyl group is involved in the shortest $\mathrm{C}-\mathrm{H} \cdots \mathrm{C}(\pi)$ contact that can be found in the crystal structure (2.909 $)$ ), with the $\mathrm{C}-\mathrm{H}$ group pointing more towards a single carbon atom $(\mathrm{C} 11-\mathrm{H} 11 \mathrm{~A} \cdots \mathrm{C} 22)$. Although weak $\mathrm{C}-\mathrm{H} \cdots \mathrm{O}$ contacts only contribute $2.2 \%$ to the intermolecular interactions in the title compound, they might play an important directional role for the crystal packing [31, 37-39]. The shortest intermolecular $\mathrm{H} \cdots \mathrm{O}$ contact that can be found is $2.756 \AA$

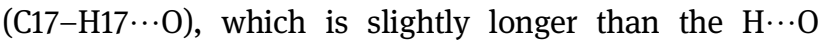
contact in the tert-butyl compound [31].

Acknowledgements: I thank Prof. Dr. Manfred Scheer for continuous support and providing laboratory facilities.

Author contributions: All the authors have accepted responsibility for the entire content of this submitted manuscript and approved submission.

Research funding: The Elite Network of Bavaria (ENB), the Bavarian State Ministry of Science and the Arts (StMWK), and the University of Regensburg are gratefully acknowledged for financial support (N-LW-NW-2016-366). Conflict of interest statement: The authors declare no conflicts of interest regarding this article.

\section{References}

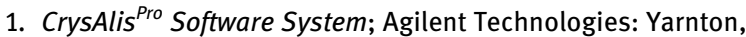
Oxfordshire, UK, 2012.

2. Sheldrick G. M. SHELXTL - integrated space-group and crystalstructure determination. Acta Crystallogr. 2015, A71, 3-8.
3. Sheldrick G. M. A short history of SHELX. Acta Crystallogr. 2008, A64, 112-122.

4. Sheldrick G. M. Crystal structure refinement with SHELXL. Acta Crystallogr. 2015, C71, 3-8.

5. Sheldrick G. M. SHELXL-2018; Universität Göttingen: Göttingen, Germany, 2018.

6. Dolomanov 0. V., Bourhis L. J., Gildea R. J., Howard J. A. K., Puschmann H. OLEX2: a complete structure solution, refinement and analysis program. J. Appl. Crystallogr. 2009, 42, 339-341.

7. Farrugia L. J. WinGX and ORTEP for Windows: an update. J. Appl. Crystallogr. 2012, 45, 849-854.

8. Spackman M. A., Jayatilaka D. Hirshfeld surface analysis. CrystEngComm 2009, 11, 19-32.

9. Spackman M. A., McKinnon J. J. Fingerprinting intermolecular interactions in molecular crystals. CrystEngComm 2002, 4, 378-392.

10. Turner M. J., McKinnon J. J., Wolff S. K., Grimwood D. J., Spackman P. R., Jayatilaka D., Spackman M. A. CrystalExplorer17; University of Western Australia: Perth, Australia, 2017.

11. Jones R. G., Ando W., Chojnowski J. Silicon-containing Polymers: The Science and Technology of Their Synthesis and Applications; Springer: Netherlands, 2000.

12. Schubert U., Hüsing N. Synthesis of Inorganic Materials, 4th ed.; Wiley-VCH: Weinheim, 2019.

13. Deschner T., Liang Y., Anwander R. Silylation efficiency of chorosilanes, alkoxysilanes, and monosilazanes on periodic mesoporous silica. J. Phys. Chem. C 2010, 114, 22603-22609.

14. Pujari S. P., Scheres L., Marcelis A. T. M., Zuilhof H. Covalent surface modification of oxide surfaces. Angew. Chem. Int. Ed. 2014, 53, 6322-6356. Angew. Chem. 2014, 126, 6438-6474.

15. Parks D. J., Piers W. E. Tris(pentafluorophenyl)boron-catalyzed hydrosilation of aromatic aldehydes, ketones, and esters. J. Am. Chem. Soc. 1996, 118, 9440-9441.

16. Rubinsztajn S., Cella J. A. A new polycondensation process for the preparation of polysiloxane copolymers. Macromolecules 2005, 38, 1061-1063.

17. Thompson D. B., Brook M. A. Rapid assembly of complex 3D siloxane architectures. J. Am. Chem. Soc. 2008, 130, 32-33.

18. Yu J., Liu Y. Cyclic polysiloxanes with linked cyclotetrasiloxane subunits. Angew. Chem. Int. Ed. 2017, 56, 8706-8710. Angew. Chem. 2017, 129, 8832-8836.

19. Bauer J. O., Stiller J., Marqués-López E., Strohfeldt K. Christmann M., Strohmann C. Silyl-modified analogues of 2tritylpyrrolidine: synthesis and applications in asymmetric organocatalysis. Chem. Eur J. 2010, 16, 12553-12558.

20. Igawa K., Kokan N., Tomooka K. Asymmetric synthesis of chiral silacarboxylic acids and their ester derivatives. Angew. Chem. Int. Ed. 2010, 49, 728-731. Angew. Chem. 2010, 122, 740-743.

21. Lainer T., Leypold M., Kugler C., Fischer R. C., Haas M. Dodecamethoxyneopentasilane as a new building block for defined silicon frameworks. Eur. J. Inorg. Chem. 2021, 529-533; https://doi.org/10.1002/ejic.202001112.

22. Bauer J. O., Strohmann C. One-step conversion of methoxysilanes to aminosilanes: a convenient synthetic strategy to $\mathrm{N}, \mathrm{O}$-functionalised organosilanes. Chem. Commun. 2012, 48, 7212-7214.

23. Bauer J. O., Strohmann C. Stereoselective synthesis of siliconstereogenic aminomethoxysilanes: easy access to highly 
enantiomerically enriched siloxanes. Angew. Chem. Int. Ed. 2014, 53, 720-724. Angew. Chem. 2014, 126, 738-742.

24. Bauer J. 0., Strohmann C. Recent progress in asymmetric synthesis and application of difunctionalized silicon-stereogenic silanes. Eur. J. Inorg. Chem. 2016, 2868-2881.

25. Barth E. R., Krupp A., Langenohl F., Brieger L., Strohmann C. Kinetically controlled asymmetric synthesis of siliconstereogenic methoxy silanes using a planar chiral ferrocene backbone. Chem. Commun. 2019, 55, 6882-6885.

26. Espinosa-Jalapa N. A., Bauer J. O. Controlled synthesis and molecular structures of methoxy-, amino-, and chlorofunctionalized disiloxane building blocks. Z. Anorg. Allg. Chem. 2020, 646, 828-834.

27. Zibula L., Achternbosch M., Wattenberg J., Otte F., Strohmann C. Influences of steric factors on the reactivity and structure of diorganoalkoxysilylamides. Z. Anorg. Allg. Chem. 2020, 646, 978-984.

28. Bauer J. O., Strohmann C. Unusual coordination pattern of the lithium center in a chiral $\alpha$-lithiated silicon compound. Organometallics 2021, 40, 11-15.

29. Wakabayashi R., Kawahara K., Kuroda K. Nonhydrolytic synthesis of branched alkoxysiloxane oligomers $\mathrm{Si}\left[\mathrm{OSiH}(\mathrm{OR})_{2}\right]_{4}(\mathrm{R}=\mathrm{Me}$, Et). Angew. Chem. Int. Ed. 2010, 49, 5273-5277. Angew. Chem. 2010, 122, 5401-5405.

30. Yoshikawa M., Tamura Y., Wakabayashi R., Tamai M., Shimojima A., Kuroda K. Protecting and leaving functions of trimethylsilyl groups in trimethylsilylated silicates for the synthesis of alkoxysiloxane oligomers. Angew. Chem. Int. Ed. 2017, 56, 13990-13994. Angew. Chem. 2017, 129, 14178-14182.
31. Bauer J. O., Espinosa-Jalapa N. A., Fontana N., Götz T., Falk A. Eur. J. Inorg. Chem. 2021, 2636-2642.

32. Wuts P. G. M., Greene T. W. Greenes Protective Groups in Organic Synthesis, 4th ed.; John Wiley \& Sons Inc.: Hoboken, 2006.

33. Brady T. P., Kim S. H., Wen K., Theodorakis E. A. Stereoselective total synthesis of (+)-norrisolide. Angew. Chem. Int. Ed. 2004, 43, 739-742. Angew. Chem. 2004, 116, 757-760.

34. Wang B., Hansen T. M., Wang T., Wu D., Weyer L., Ying L., Engler M. M., Sanville M., Leitheiser C., Christmann M., Lu Y., Chen J., Zunker N., Cink R. D., Ahmed F., Lee C.-S., Forsyth C. J. Total synthesis of phorboxazole a via de novo oxazole formation: strategy and component assembly. J. Am. Chem. Soc. 2011, 133, 1484-1505.

35. Nishio M., Umezawa Y., Honda K., Tsuboyama S., Suezawa H. CH/ $\pi$ hydrogen bonds in organic and organometallic chemistry. CrystEngComm 2009, 11, 1757-1788.

36. Bauer J. O., Götz T. Chloropentaphenyldisiloxane - model study on intermolecular interactions in the crystal structure of a monofunctionalized disiloxane. Chemistry 2021, 3, 444-453.

37. Steiner T. Unrolling the hydrogen bond properties of $\mathrm{C}-\mathrm{H} \cdots \mathrm{O}$ interactions. Chem. Commun. 1997, 727-734; https://doi.org/ 10.1039/a603049a.

38. Bauer J. 0 . The crystal structure of the first ether solvate of hexaphenyldistannane $\left[\left(\mathrm{Ph}_{3} \mathrm{Sn}\right)_{2} \cdots 2 \mathrm{THF}\right]$. Main Group Met. Chem. 2020, 43, 1-6.

39. Bauer J. 0. Crystal structure and Hirshfeld surface analysis of trimethoxy(1-naphthyl)silane - intermolecular interactions in a one-component single-crystalline trimethoxysilane. Z. Anorg. Allg. Chem. 2021, 647, 1053-1057. 